\title{
Study on the Pledge Rate of Inventory Pledge Financing Business Considering Financing Business Risks
}

\author{
Daoyuan $\mathrm{Ji}^{1, \mathrm{a}}$, Ruiping Gao ${ }^{2, \mathrm{~b}}$ and Xuelei Lin ${ }^{3, \mathrm{c}}$ \\ ${ }^{1}$ Physics Department of Jacobs University, Bremen 28719, Germany \\ ${ }^{2}$ Traffic and Transport School of Beijing Jiaotong University, Beijing 100044, China \\ ${ }^{3}$ Zhaoyuan Branch of Yantai Bank Incorporation, Zhaoyuan 265400, China \\ ad.ji@jacobs-university.de, ${ }^{\text {b }}$ shwji@bjtu.edu.cn, ${ }^{\text {c}} 907458704 @ q q . c o m$
}

Keywords: Inventory Pledge Financing; Pledge rate; Financing business risk; Value at Risk

\begin{abstract}
A reasonable pledge rate is essential to risk control on inventory pledge financing (IPF). Value at Risk (VAR) method is often used to calculate the pledge rate, but the method reckoned without the business risk. this paper embeds the risk assessment value of IPF business into the VAR model, and get a modified model to calculate the pledge rate. The new model can get the reasonable pledge rate varying with financing risk. this paper verifies the feasibility of the proposed model through case analysis.
\end{abstract}

\section{Introduction}

In the risk control of inventory pledge financing (IPF) business, the determination of pledge rate is clearly very significant. On the one hand, in order to ensure bank credit security, commercial banks need to determine the appropriate pledge rate to prevent the risks brought by factors such as changes in the market price of the pledged goods during the term of the loan. On the other hand, financing companies want to get more loans with fewer collaterals. In addition, during the management of the pledge, logistics enterprises need to set a reasonable stock control index according to the pledge rate.

In the study of pledge rate, Jokivuolle and Peura et al. established a risk-based debt model based on the correlation between the value of collateral and the probability of firm default [1]. Wang Yong-zhong designed a pledge model of IPF by VAR method aiming at the pledge of random fluctuation of price [2]. Under the dynamic logistics regulatory approach, Gao Jie took into account the impact of price volatility and the credit quality of the collateral goods and established the calculation model based on the pledge of batches of lading [3].

The above studies mostly consider the pledge rate from the inventory market price changes, concealing the different risks of IPF business. At the beginning this paper analyzes the VAR method of calculating the pledge rate which considers the market price of pledges. Then it gets the improved model of pledge rate that changes with the size of financing risk by introducing the risk assessment value of IPF business into VAR model. Finally, the paper analyzes the examples and verifies the feasibility of the algorithm.

\section{Pledge Rate Determination Based on VAR Method}

Value at risk refers to the maximum possible loss of the expected value of an asset or a portfolio within a given confidence level and time interval under normal market price fluctuations [4]. In this paper its value is assumed as Var.

In this paper, from the perspective of the price of goods market, the historical simulation method is used to calculate Var to determine the pledge rate. The calculation model of pledge rate $k$ is as follows:

$$
F=Q * P * k=Q *(1-\Delta P / 2 P) *(P-V a r)
$$




$$
\begin{aligned}
& k=(1-\Delta P / 2 P) * \xi \\
& \xi=(P-\text { Var }) / P
\end{aligned}
$$

Where $F$ represents pledge amount; $Q$ represents the number of goods regulated by the logistics enterprise; $P$ represents the unit market price of the goods pledged in the current cycle; pledge rate is $k$, also marked as VAR_k; $\Delta P$ represents the maximum price fluctuations of the goods in the past two years; $\xi$ represents the market risk control factor of the loan amount; when the value of $\Delta P / P$ is larger, the price of this kind of goods fluctuates relatively more, so the risk is relatively larger and the value of $\xi$ is smaller. The key of this model is to determine Var [5]

The basic calculation steps to get Var are as follows [6]:

Step 1: Calculate the periodic rate of return of each unit cycle $R t$, that is: $R t=P t / P_{t-1}-1$;

Step 2: According to the periodic rate of return series, simulate a pledge price after a cycle $P_{t-1}^{\prime}$, that is $P_{t-1}^{\prime}=P_{t}\left(1+R_{t}\right)$. And obtain the simulated change value of spot price of pledged goods $\Delta P$, that is $\Delta P=P_{t-1}^{\prime}-P_{t}$.

Step3: Sort the price change values, and find the smallest $\alpha \%$ of all the simulated change values.

Step4: Use the minimum value in step 3 or $R^{\prime}$ corresponding to its average value to find Var, that is $\operatorname{Var}=R^{\prime *} P_{t}$.

\section{Pledge Rate Determination Based on Risk Evaluation Value (REV) Method}

The VAR method can adjust the pledge rate more effectively according to the fluctuation of the market price of goods. However, it takes less consideration of the overall risk of other financing businesses and has a fixed pledge rate for the same type of goods. It cannot effectively reflect risk changes in financing business caused by the variations of different financing enterprises, different logistics enterprises and industry factors.

For the risk of IPF business itself, effective control can be achieved by adjusting the pledge rate. For high-risk credit businesses, a lower pledge rate may be set to effectively control the loss when the risks happen. For low-risk credit businesses, a higher pledge rate may be set to save customers' pledge cost, improve customer relationships and maintain existing customer base while saving the cost of risk prevention,

The strategy adopted in this paper is: when the risk assessment value of the inventory pledge financing business is at the highest value $V \max$ in the actual credit business, the lowest pledge rate $k_{m i d}$ in the actual pledge control operation is used to control the risk; when the risk assessment value of the inventory pledge financing business is at the average value $V_{\text {mid }}$ in the actual credit business, the average pledge rate $k$ mid in the actual pledge control operation is used to control the risk, and when the risk assessment value of the inventory pledge financing business is at the lowest value $V_{\min }$ in the actual credit business, the highest pledge rate $k_{\max }$ in the actual pledge control operation is used to control the risk.

Based on this strategy, this paper introduces the interval change value of the inventory pledge financing business risk assessment value to adjust the pledge rate $k$, as follows:

$k=\left[1+\frac{\left(V_{\text {mid }}-V\right)}{\left(V_{\text {max }}-V_{\text {min }}\right)} * \frac{\left(k_{\text {max }}-k_{\text {min }}\right)}{k_{\text {mid }}}\right] * k_{\text {mid }}$

In the formula, $k_{\max } 、 k_{\operatorname{mid}} 、 k_{\min }$ respectively represent the highest pledge rate the average pledge rate and the lowest pledge rate of the inventory pledge financing business; $V_{\max } 、 V_{\text {mid }} 、 V_{\min }$ respectively represent the highest risk assessment value、 the average risk assessment value and the lowest risk assessment value of the allowed inventory pledge financing business.

From the formula (4) we can see that the size of the risk assessment value $V$ of the inventory pledge financing can also be used to determine the pledge rate and the pledge rate $k$ is recorded as $V$ $-k$ by this way. The change of the risk assessment value $V$ will result in the change of the pledge 
rate $k$.

Therefore, for a single inventory pledged financing business, we can use the formula (4) to determine the pledge rate based on the risk evaluation result of the business. This method can effectively reflect the business risk size, and we call it the pledge rate calculation model based on the risk assessment value.

At the same time, we find that there is a ratio relationship between the new pledge rate $k$ resulting from a change in the risk assessment value $V$ and the average pledge rate $k$ mid in the goods pledge business field. We can set this ratio as the influence coefficient of the risk assessment value $V$ on the pledge rate $k$. Let the coefficient be $\theta$, then:

$\theta=\left[1+\frac{\left(V_{\text {mid }}-V\right)}{\left(V_{\text {max }}-V_{\text {min }}\right)} * \frac{\left(k_{\max }-k_{\min }\right)}{k_{\text {mid }}}\right]$

\section{An Example Calculation}

In order to expand the production capacity and obtain the working capital, X Copper Company applied the copper products stored in C Logistics Company to S Bank to apply for the logistics finance loan business. Suppose the value of the market risk fluctuation of the copper pipe Var in the coming month is 2728 . The greatest price fluctuation $\Delta P$ in the recent two years is 40604 , and the spot price of copper pipe this month is 64778. Based on Var value pledge rate method, we have:

$$
k=\frac{(2 P-\Delta P)}{2 P} * \frac{(P-V a r)}{P}=\left(1-\frac{40604}{2 * 64778}\right) * \frac{(64778-2728)}{64778}=0.658
$$

According to the actual business risk size, we can assume $V_{\max }=0.75, V_{\text {mid }}=0.5, V_{\min }=0.25$. In the business practice of cargo pledge, the pledge rate is generally $60 \% \sim 70 \%$, and the highest is not more than $80 \%$, so we can assume $k_{\max }=80 \%, k_{\text {mid }}=65 \%, k_{\min }=50 \%$.

According to the different risk assessment values, we use two different pledge rate calculation models to calculate the pledge rate, and the results are shown in Table 1:

Table 1 the Pledge Rate of Two Different Calculation Methods

\begin{tabular}{|c|c|c|c|c|c|c|}
\hline Risk Assessment Value & $\mathbf{0 . 2}$ & $\mathbf{0 . 2 5}$ & $\mathbf{0 . 3}$ & $\mathbf{0 . 3 5}$ & $\mathbf{0 . 4}$ & $\mathbf{0 . 4 5}$ \\
\hline pledge rate calculated by VAR method & 0.658 & 0.658 & 0.658 & 0.658 & 0.658 & 0.658 \\
\hline pledge rate calculated by REV method & 0.83 & 0.8 & 0.77 & 0.74 & 0.71 & 0.68 \\
\hline Risk Assessment Value & $\mathbf{0 . 5}$ & $\mathbf{0 . 5 5}$ & $\mathbf{0 . 6}$ & $\mathbf{0 . 6 5}$ & $\mathbf{0 . 7}$ & $\mathbf{0 . 7 5}$ \\
\hline pledge rate calculated by VAR method & 0.658 & 0.658 & 0.658 & 0.658 & 0.658 & 0.658 \\
\hline pledge rate calculated by REV method & 0.658 & 0.627 & 0.597 & 0.567 & 0.536 & 0.506 \\
\hline
\end{tabular}

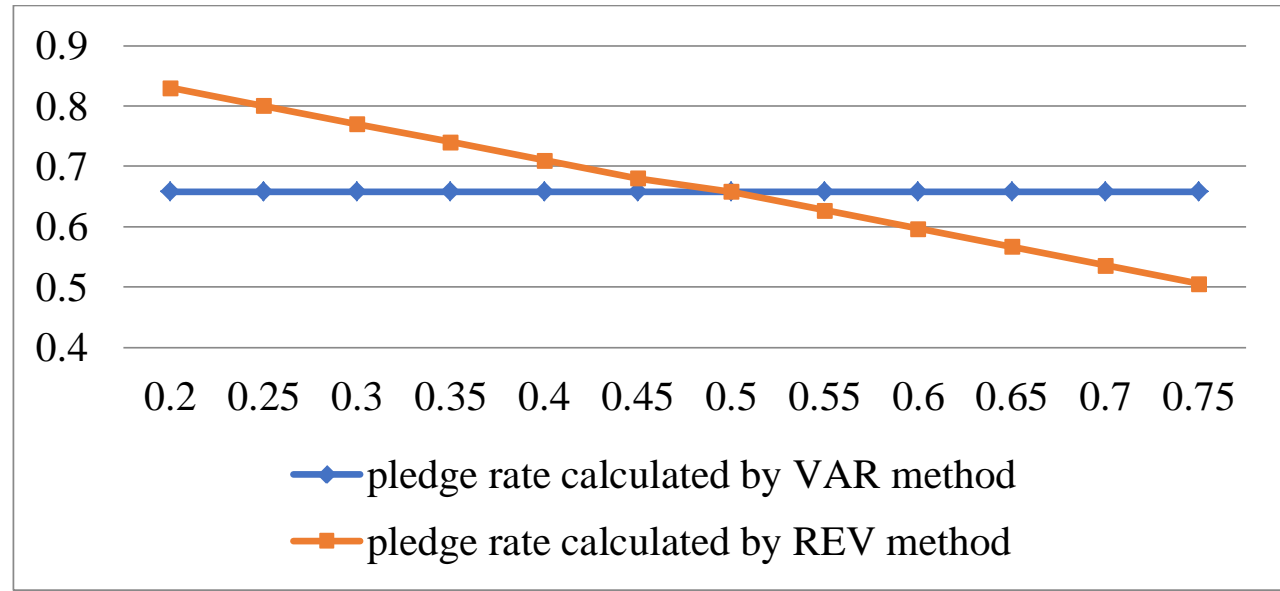

Figure1 the Pledge Rate to Different Methods under Different Risk Measure Value 
From Table 1 and Figure 1, we can see that the pledge rate calculated by VAR method is a fixed value, which cannot reflect the difference of the loan business risk of the same type of goods in situation of different credit business risk assessment values. But the pledge rate determined by REV method can better reflect the change of the loan business risk, which can adjust the pledge rate according to its value to effectively prevent the default risk caused by the risk of the loan business itself.

And at the same time, we can see that when the price fluctuation of goods approaches the normal level and the risk assessment approaches the non-grant loan, the pledge rate determined by the REV method is close to the lower bound of the practical application; furthermore, when the risk assessment approaches the high-quality credit business, the pledge rate determined by the REV method is also relatively low, which is close to the upper bound of the practical application. Such a pledge rate keeps a good consistency with the IPF risk.

\section{Conclusion}

This paper modifies the VAR value calculation model of the pledge rate, and then builds a new calculation model of the pledge rate based on the business risk. The new model can reflect not only the specific risks of IPF business, but also the dynamic risks of goods price fluctuation. In the future, other financing risk factors will be considered to optimize the calculation of quantifying the pledge rate.

\section{References}

[1] Jokivuolle E, Peura S.Incorporating collateral value uncertainty in loss given default estimates and loan-to-value ratios[J].European Financial Management,2003 9(3) 299-314.

[2] Gong Yongzhong. Problem analysis of the warehouse list loan and the VAR design of the key indicators [D]. Xi'an: Northwestern Polytechnical University, 2004.

[3] Gao Jie. Research on Loan-to-Valule ratios in the mode of dynamic logistic supervision and control [J]. Logistics Engineering and Management, 200910 39-40.

[4] Gao Hong, Fang Shufen. VaR method for evaluating the ratios of warehouse list loan[J]. Railway Purchase and Logistics, 2007 11 18-19.

[5] Liu Jinming. Research on risk management of warehouse receipt pledging [D]. Beijing: Beijing Jiaotong University, 2007.

[6] Zheng Qingyu. The method of determining inventory pledge rate through VAR, [J]. Decision and Information, 20095 167-168. 